\title{
Comparison of the Effectiveness Behavioral Activation Treatment Therapy and Acceptance and Commitment Therapy on Executive Functions of Learning the Rules, Inhibiting Impulsivity, and Flexibility in Patients with Depression
}

\author{
Sahar Amiri, Parvin Ehtesham Zadeh*, Fariba Hafezi, Mohamad Reza Borna
}

Department of Psychology, Ahvaz Branch, Islamic Azad University, Ahvaz, Iran

\section{ABSTRACT}

Introduction: Little attention has been paid to the impairment of executive functions (EF) in depression disorders when evaluating the effectiveness of therapies. The aim of this study was to evaluate and compare the effects of two important therapies of behavioral therapy approach, namely therapy based on Behavioral Activation Therapy (BA) and Acceptance and Commitment Therapy (ACT) on the three executive function components of inhibition, learning rules, and flexibility in patients with depression. Materials and Methods: This research was quasi-experimental field research with a pre-posttest and control group with a three-month follow-up. The statistical population of the study consisted of all clients diagnosed with depression in the psychology and counseling centers of Ahvaz in 2019. Forty-five of them were selected by purposive sampling and randomly assigned to two experimental groups and one control group. To collect the data Tower Test and Word Context Test of D-KEFS were used. Results: The results showed that ACT and BA significantly improve the learning of rules, inhibition, and mental flexibility of subjects with depression immediately after treatment. However, the effectiveness of BA on learning the rules and inhibition was significantly higher than ACT. In the follow-up phase, only the effectiveness of BA on the two components of rule learning and inhibition remained stable, and ACT did not retain its effectiveness on any of the components of EF after a two-month period. Conclusion: Considering the different range of intensity and duration of effect of BA and ACT on different EF components of patients with depression, our findings can be useful for selecting and designing the most appropriate treatment approach according to the needs of each patient.

\section{Keywords:}

1. Depression

2. Acceptance and Commitment Therapy

3. Psychology

*Corresponding Author: Parvin Ehtesham Zadeh

Email: P_ehtesham85@yahoo.com 


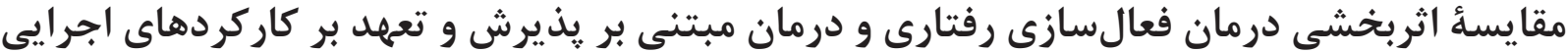

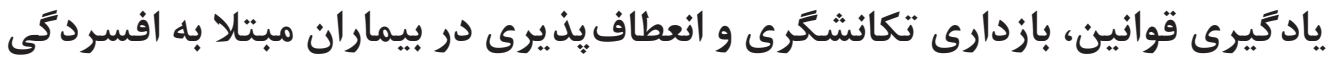

سحر اميرى، يروين احتشامزاده"، فريبا حافظى، محمدرضا برنا

كروه روانشناسى، واحد اهواز، دانشًاه آزاد اسلامى، اهواز، ايران

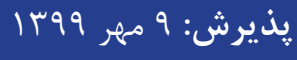

\section{اطلاعات مقاله:}

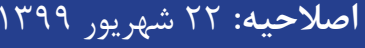

دريافت: ·r مرداد وجسا

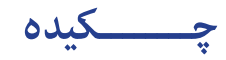

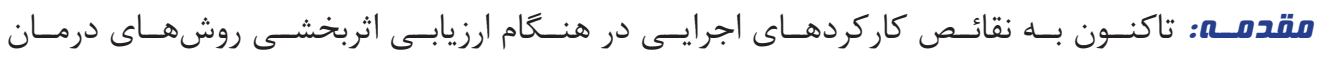

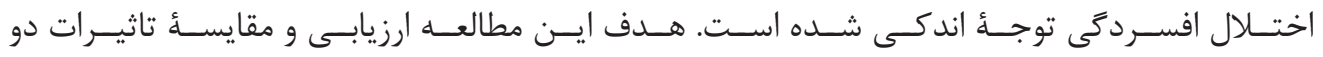

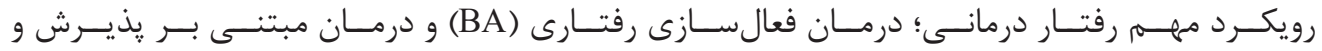

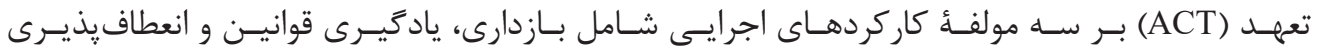

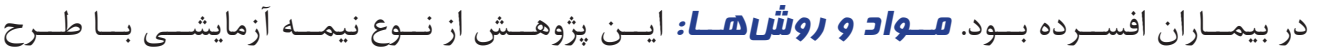

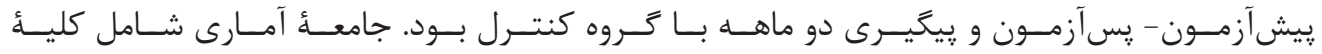

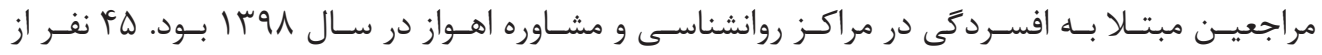

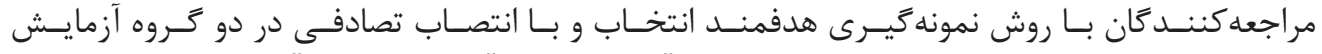

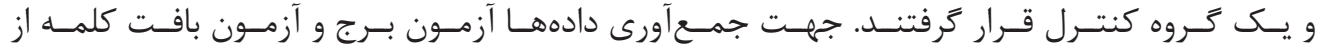

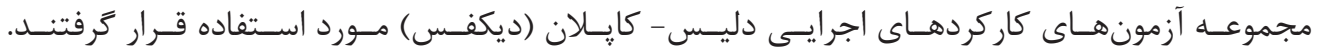

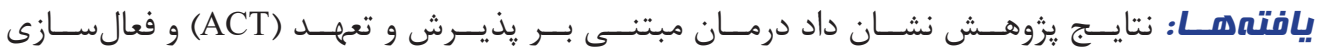

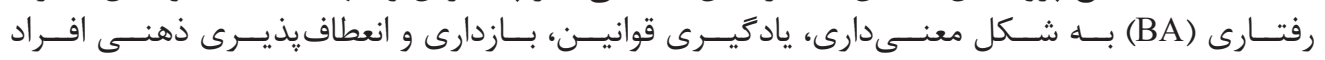

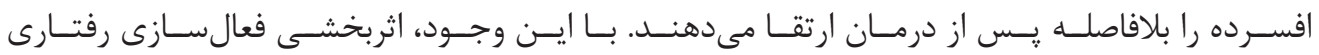

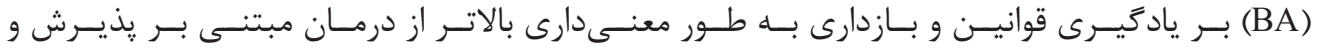

وازههاى كليدى:

ا

r

تعهد

r- روانشناسى

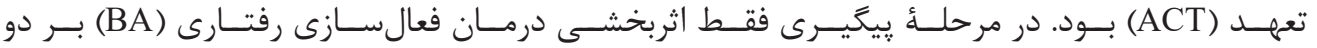

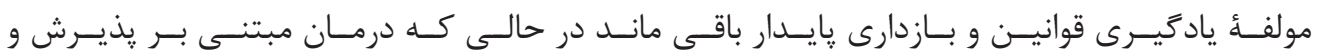

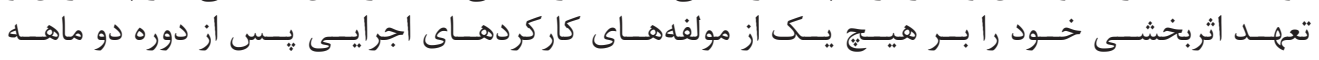

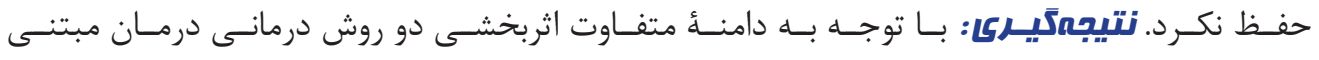

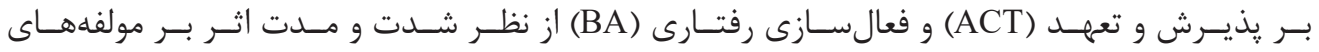

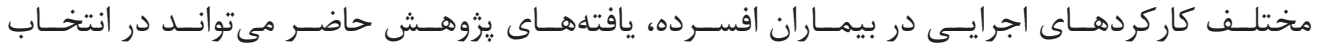

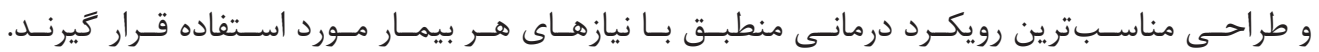




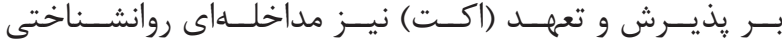

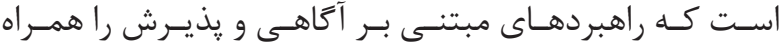

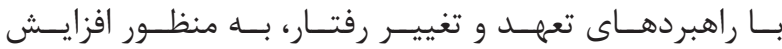

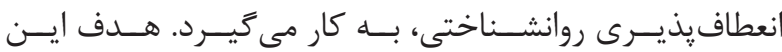

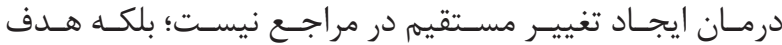

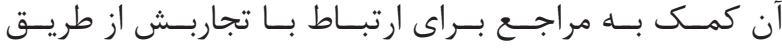

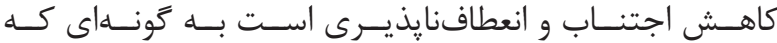

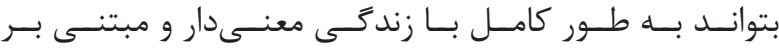

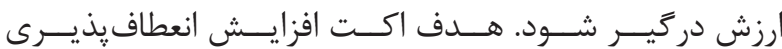

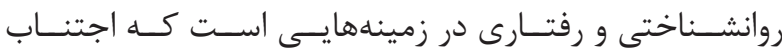

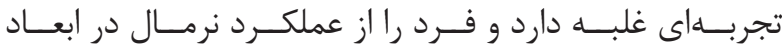

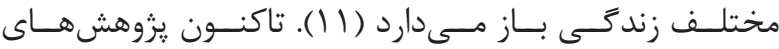

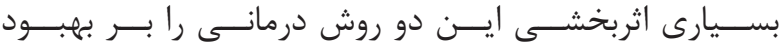

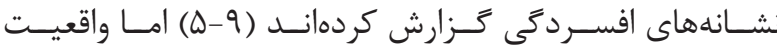

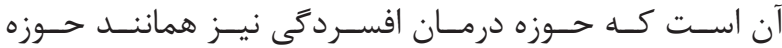

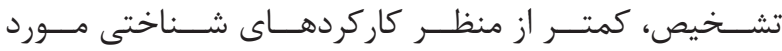

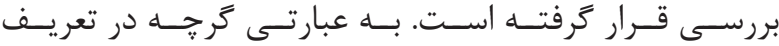

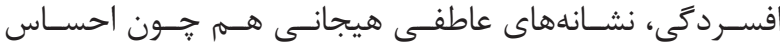

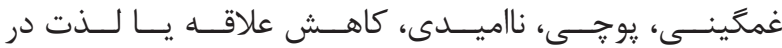

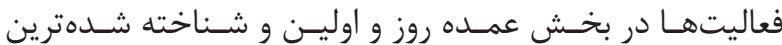

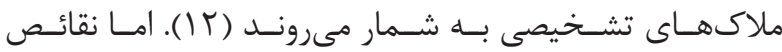

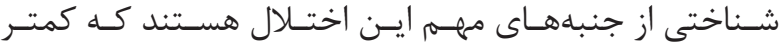

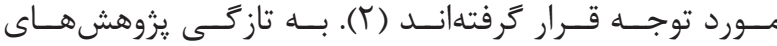

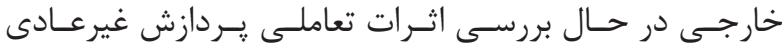

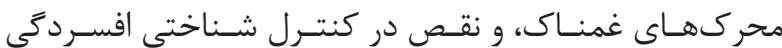

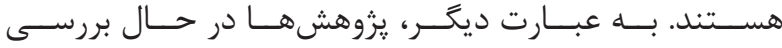

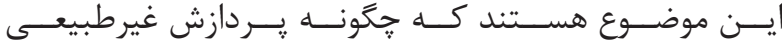

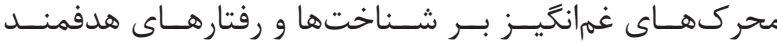

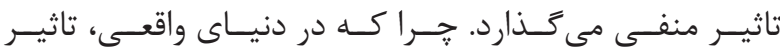

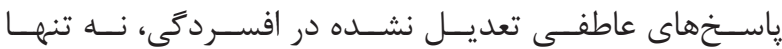

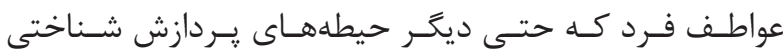

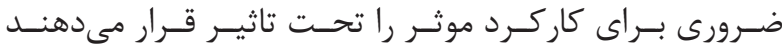

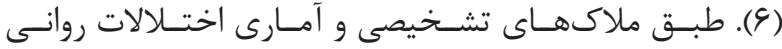

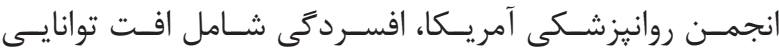

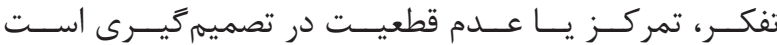

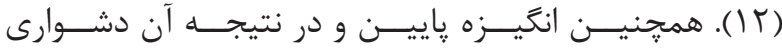

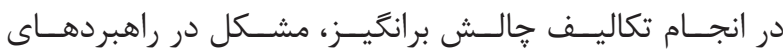

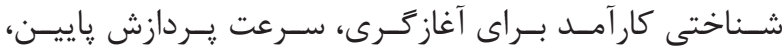

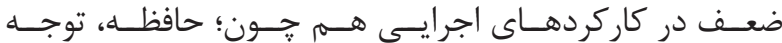

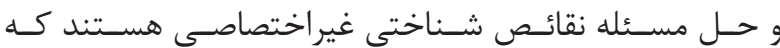

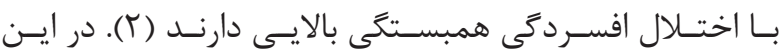

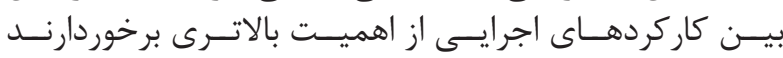

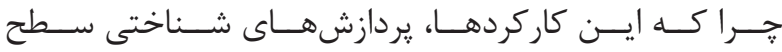

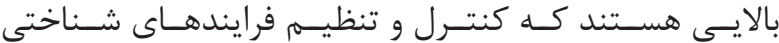

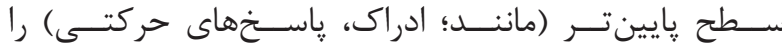

مقدمه - مق

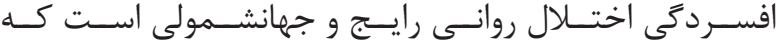

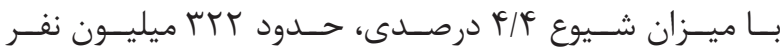

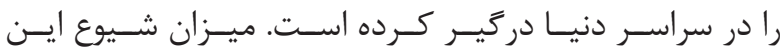

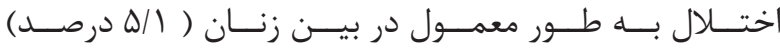

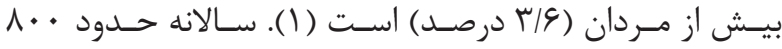

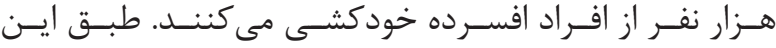

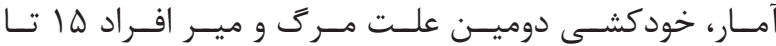

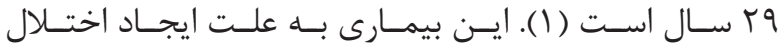

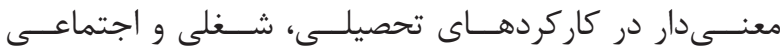

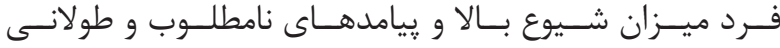

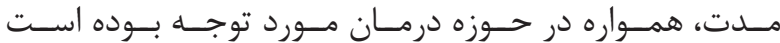

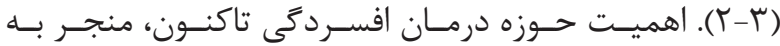

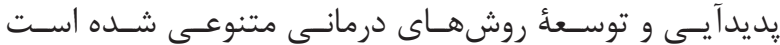

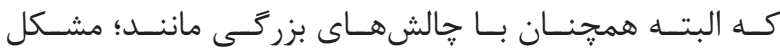

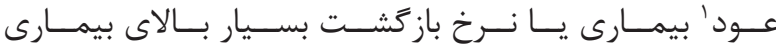

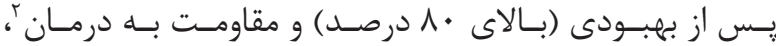

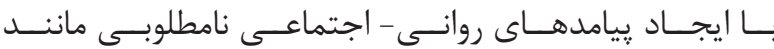

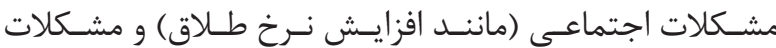

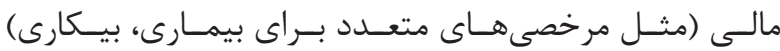

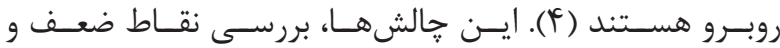

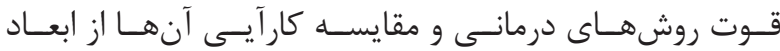

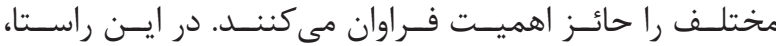

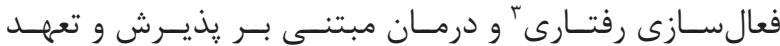

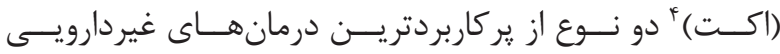

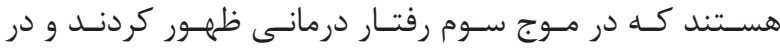

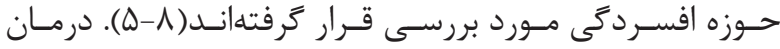

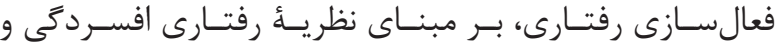

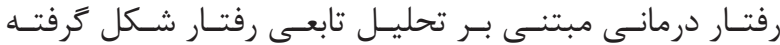

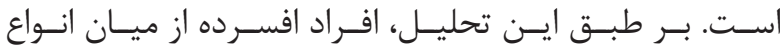

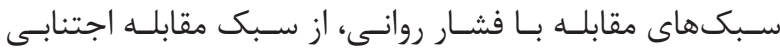

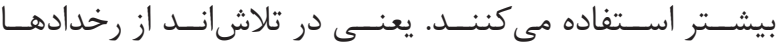

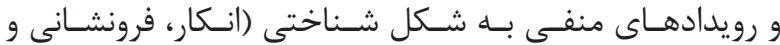

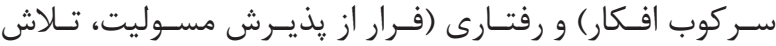

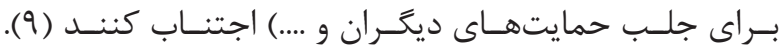

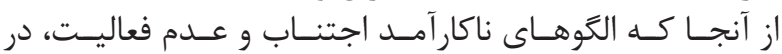

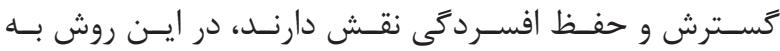

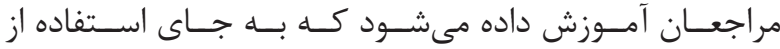

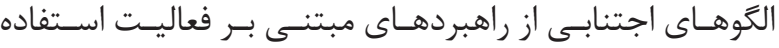

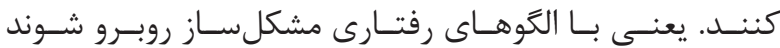

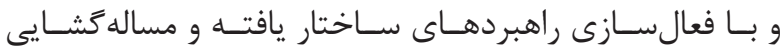

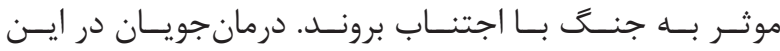

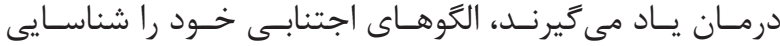

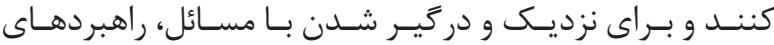

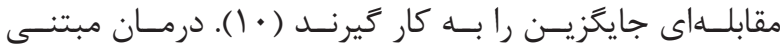




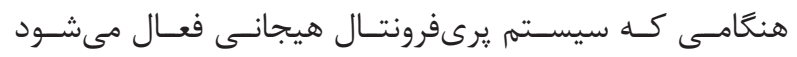

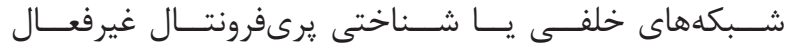

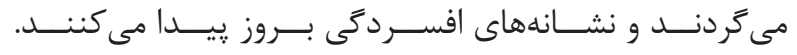

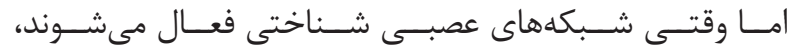

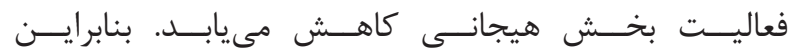

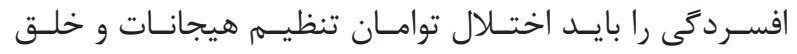

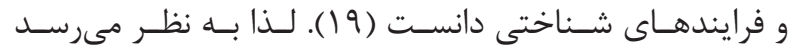

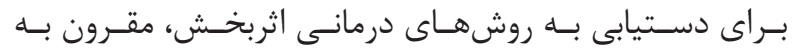

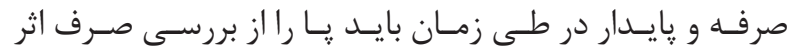

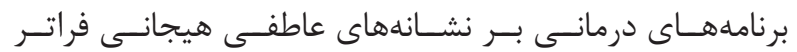

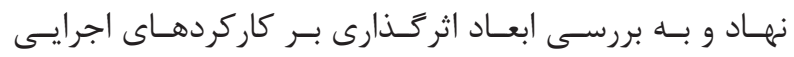

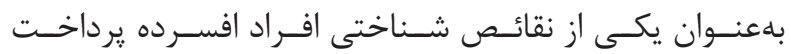

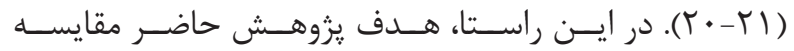

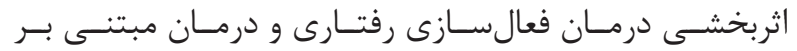

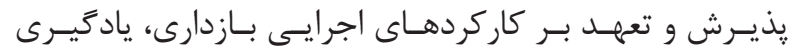

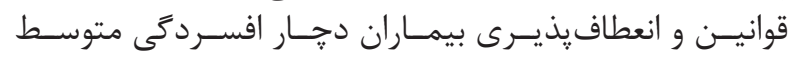

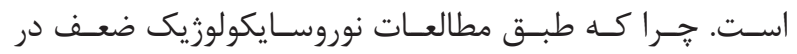

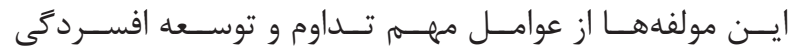

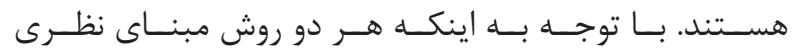

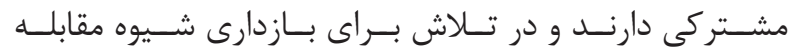

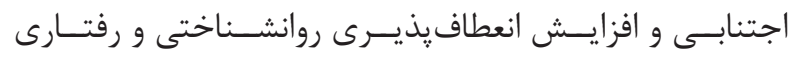

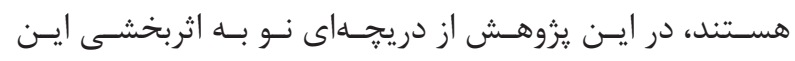

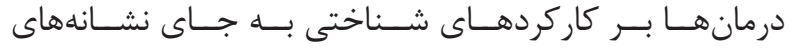
هيجانسى عاطفـى مى يردازيـهم.

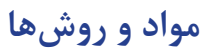

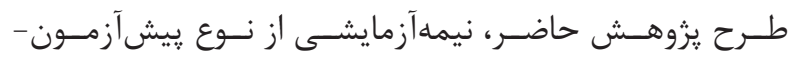

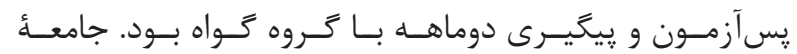

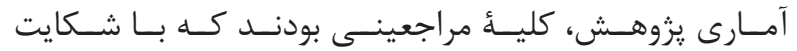

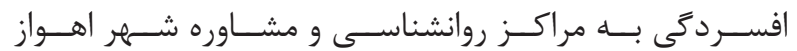

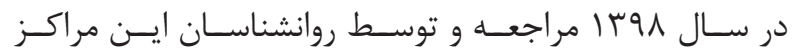

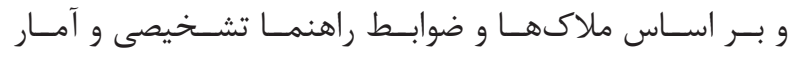

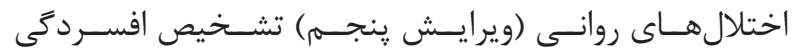

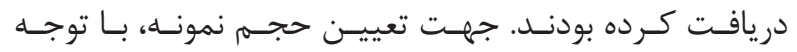

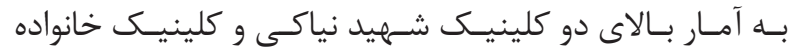

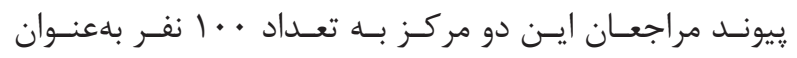

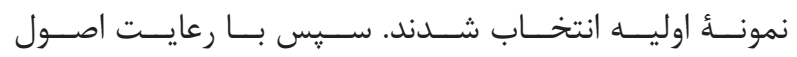

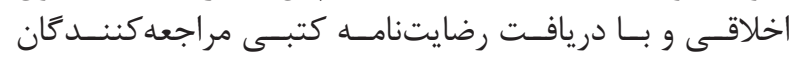

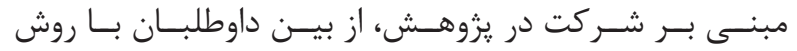
نمونه

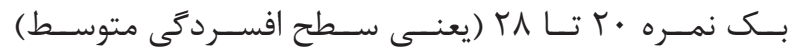

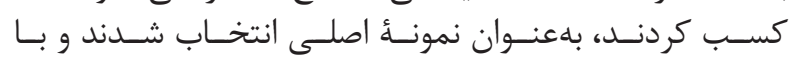

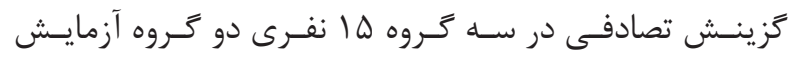

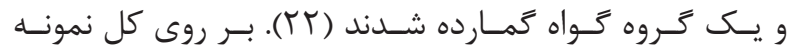

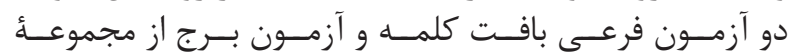

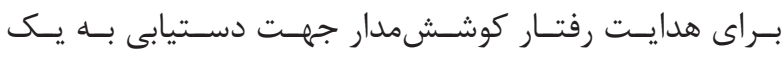

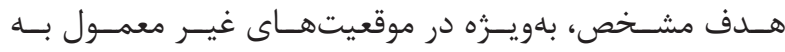

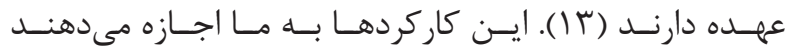

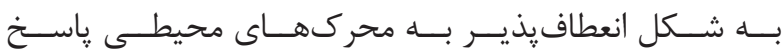

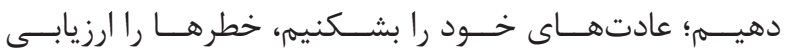

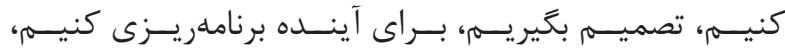

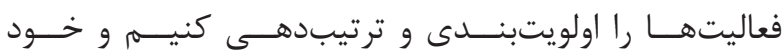

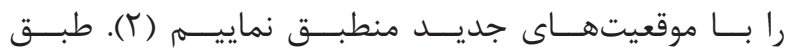

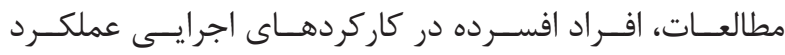

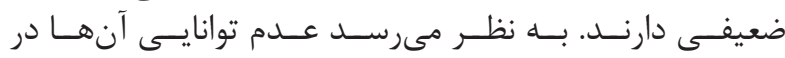

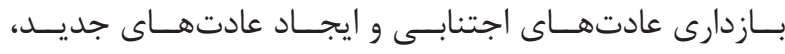

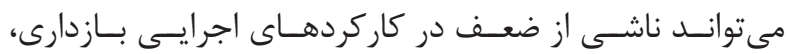

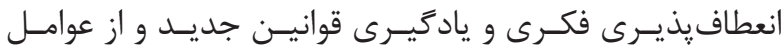

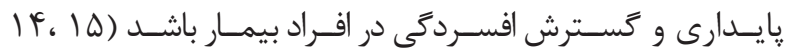

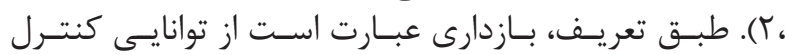

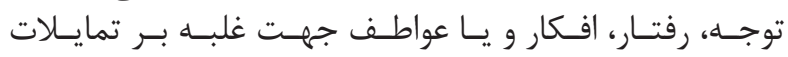

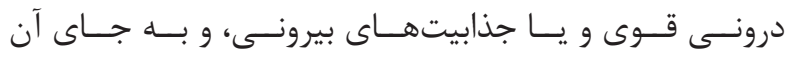

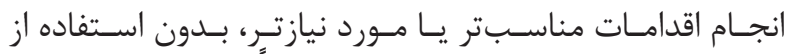

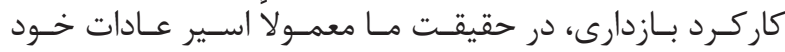

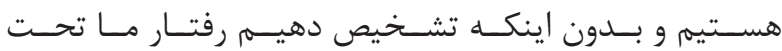

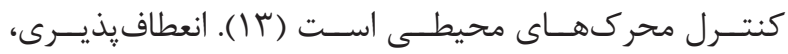

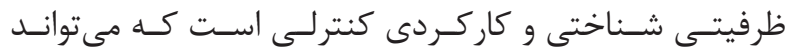

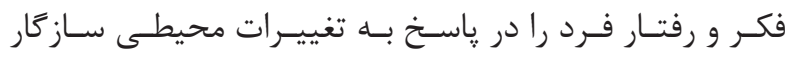

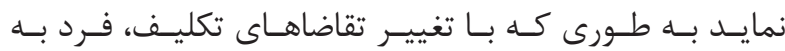

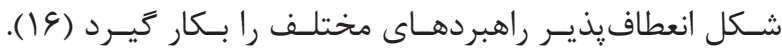

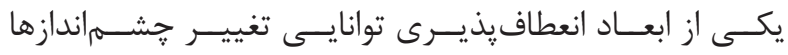

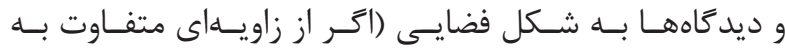

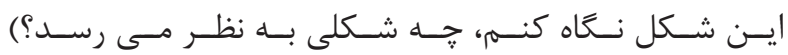

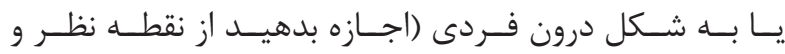

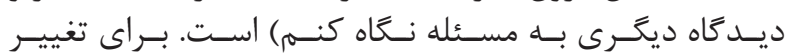

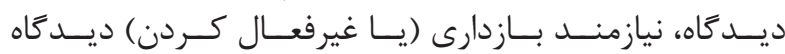

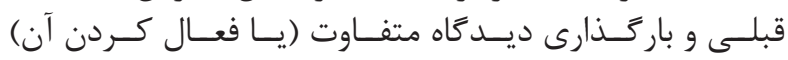

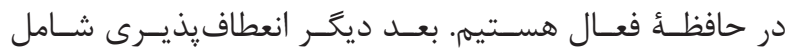

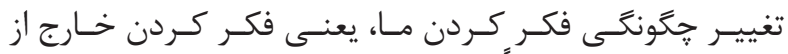

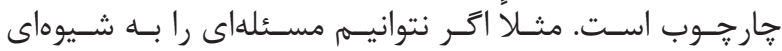

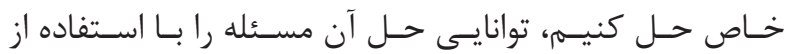

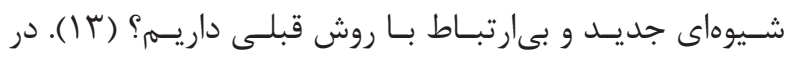

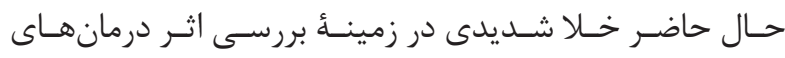

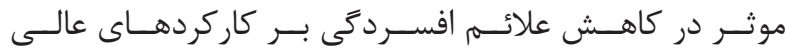

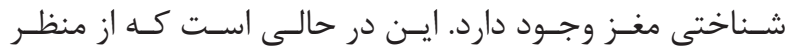

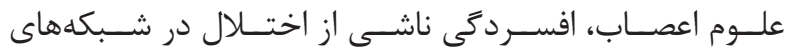

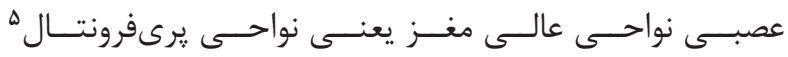

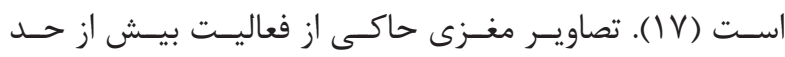

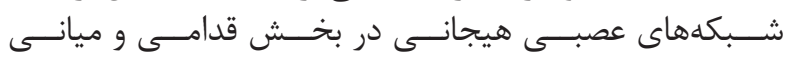

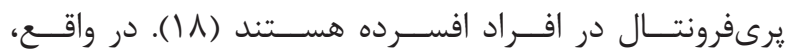


ابــزار درجهبنـــى تشـخيص مــورد اسـتفاده قــرار كرفــت.

\section{آزمون كاركردهاى اجرايى دليس- كايلان (ديكفس)}

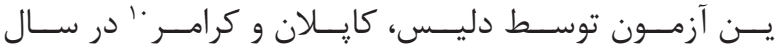

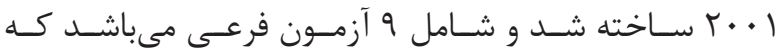

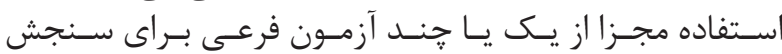

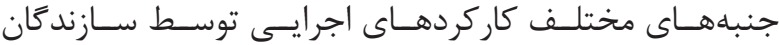

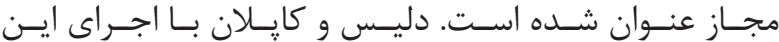

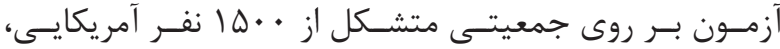

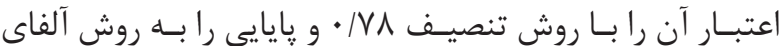

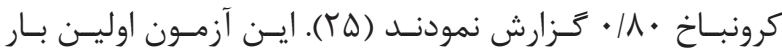

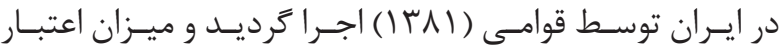

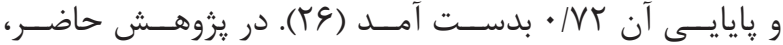

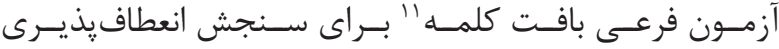

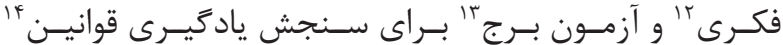

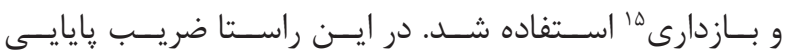

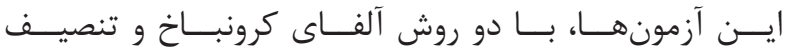

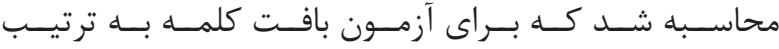

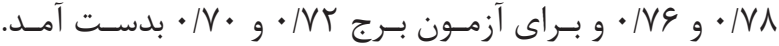

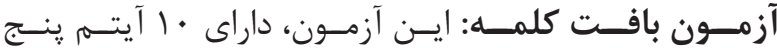

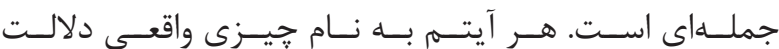

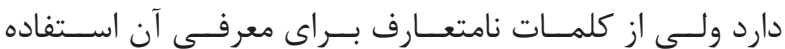

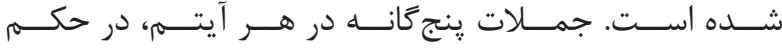

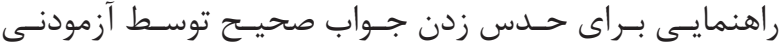

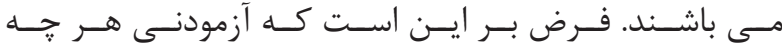

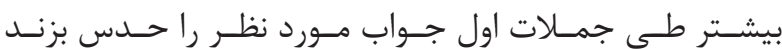

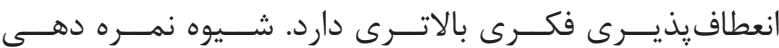

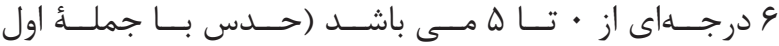

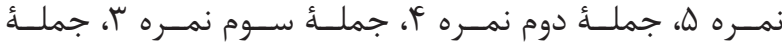

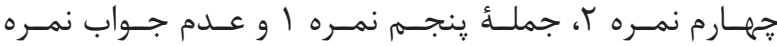

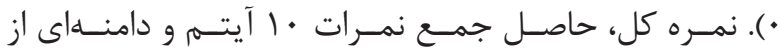

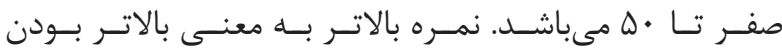

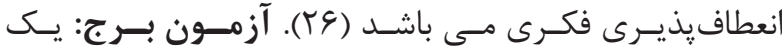

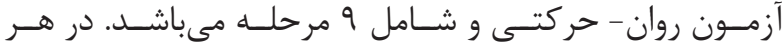

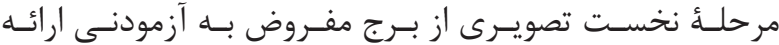

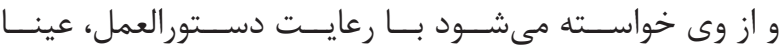

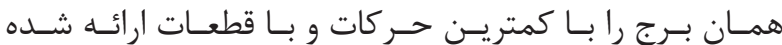

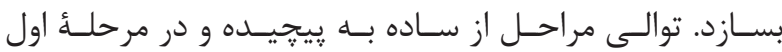

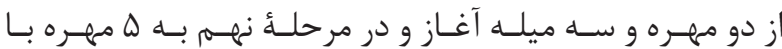

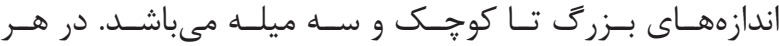

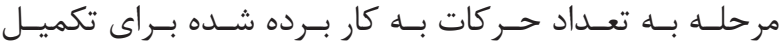

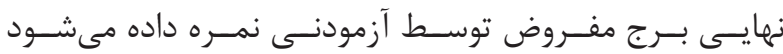

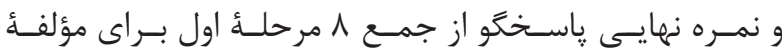

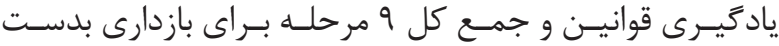

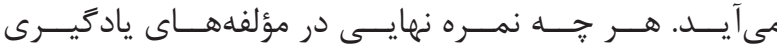

\footnotetext{
${ }^{6}$ Canter \& Buosh \& Rash

${ }^{7}$ Band \& Hays

${ }^{8}$ Beck's Depression Questionnaire

${ }^{9}$ Beck, Brown \& Steer

${ }^{10}$ Delis, Kaplan and Kramer
}

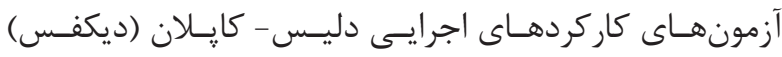

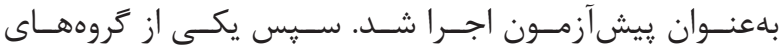

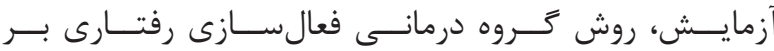

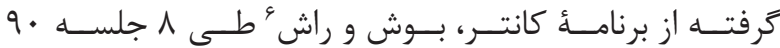

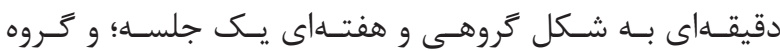

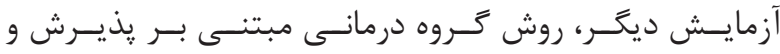

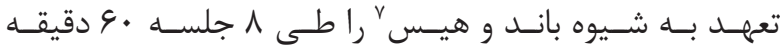

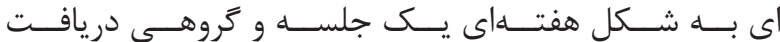

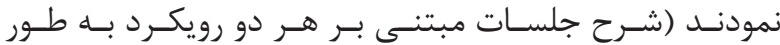

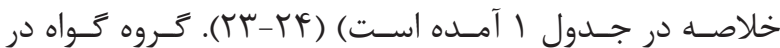

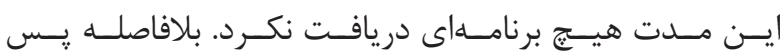

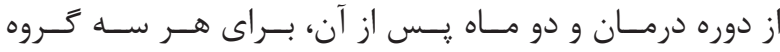

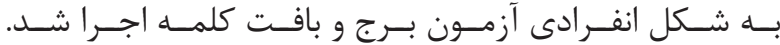

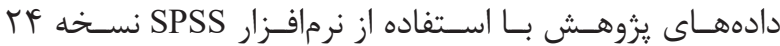

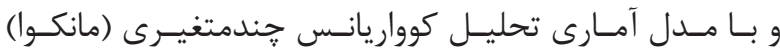

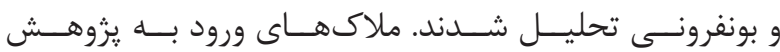

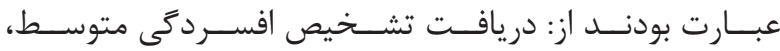

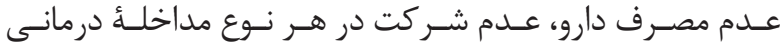

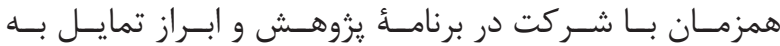

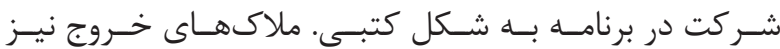

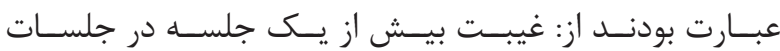

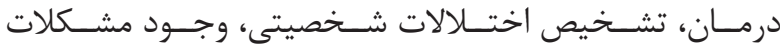

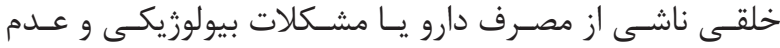

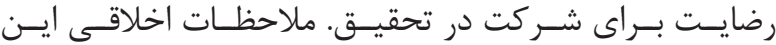

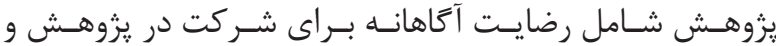

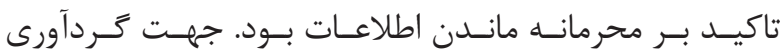

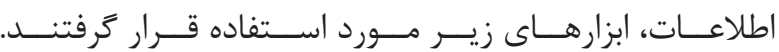

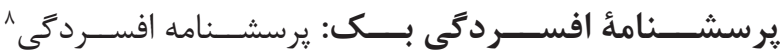

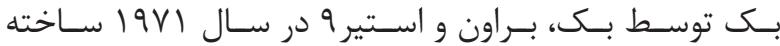

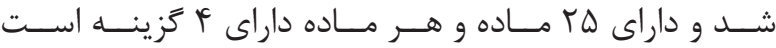

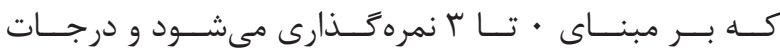

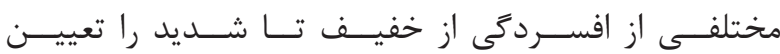

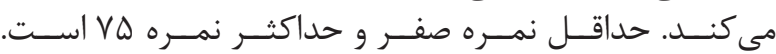

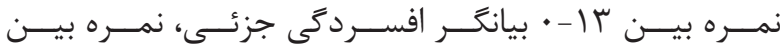

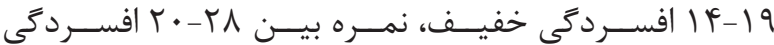

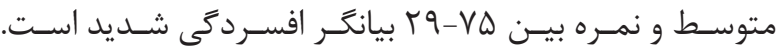

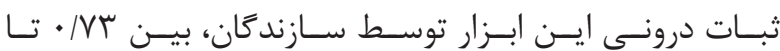

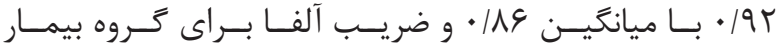

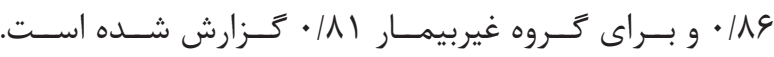

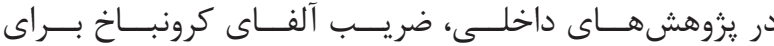

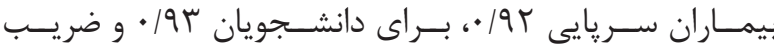

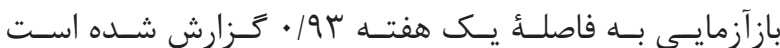

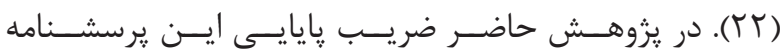

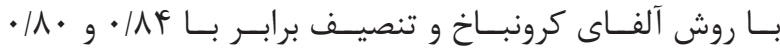

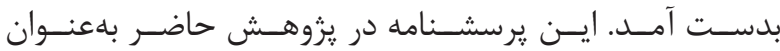

${ }^{11}$ Word Texture

${ }^{12}$ Flexibility of Thinking

${ }^{13}$ Tower Test

${ }^{14}$ Learning the Rules

${ }^{15}$ Inhibiting 


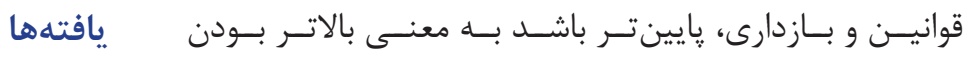

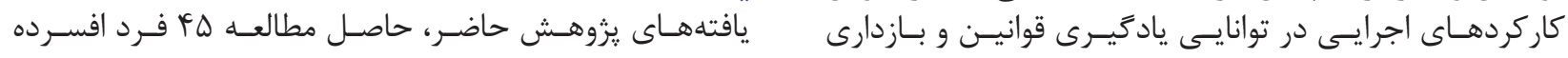

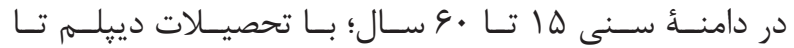

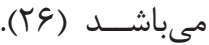

جدول ا- خلاصه برنامه درمان فعالسازى رفتارى و درمان مبتنى بر تعهد و يذيرش (اكت)

\begin{tabular}{|c|c|c|}
\hline محتواى جلسات درمان مبتنى بر تعهل و يذيرش & محتواى جلسات درمان فعالسازى رفتارى & جلسه \\
\hline معرفى اعضا، بيان قواعد كروه، اهداف و معرفى دوره & برقرارى ارتباط و معرفى اعضا، بيان اهداف و معرفى دوره و آموزش & 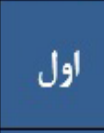 \\
\hline 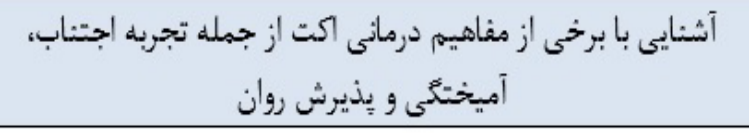 & تمركز فعالسازى رفتارى بر تعامل بين فرد و محيط & 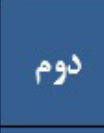 \\
\hline اجراى فثوندرمانى (اكت) مانثد جداسازى شثاختى، آثاهى روانى، & 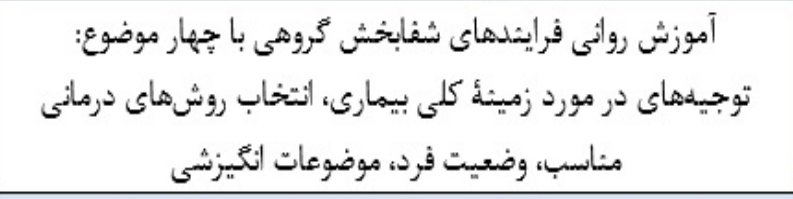 & 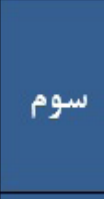 \\
\hline 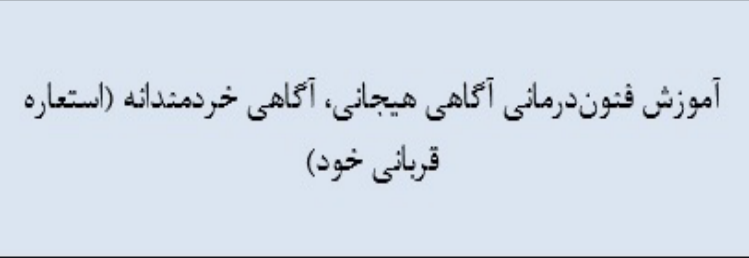 & 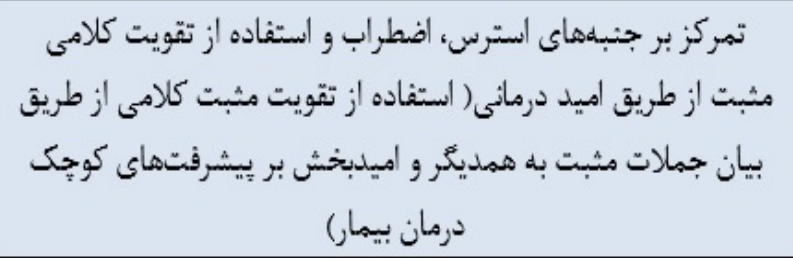 & 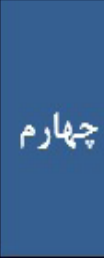 \\
\hline آموزش فنوندرمانى خود بنعنوان زميثه و تمرين فثون ذهن & تمركز بر جنبههاى افسردكى و تغيير حالات خلقى و روانى از طريق استفاده از تمثيل & | ينجمم \\
\hline 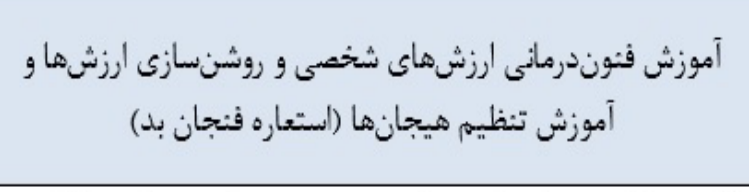 & 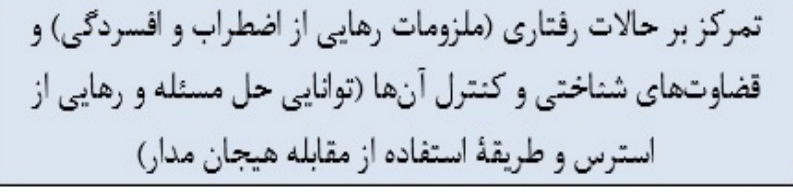 & ششم \\
\hline 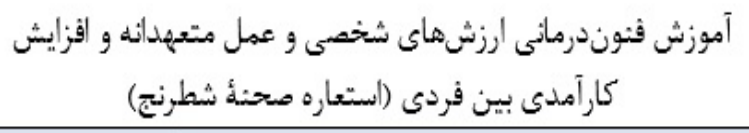 & 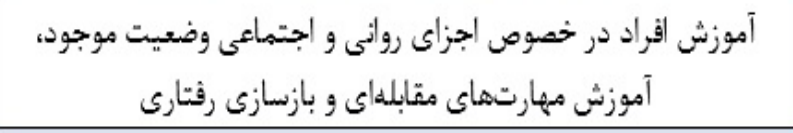 & 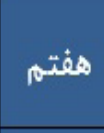 \\
\hline 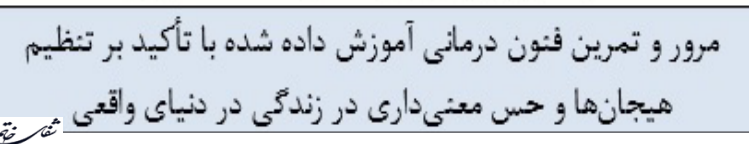 & ارائه خلاصه درمان به شكل كوتاه و راهكارهاى بيّئرانه و نظر خواهى & هشتم \\
\hline
\end{tabular}

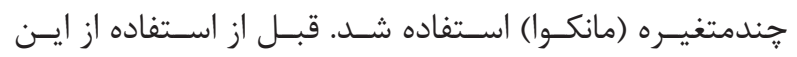

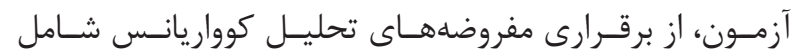

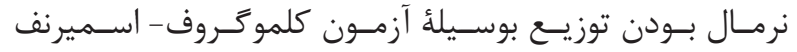

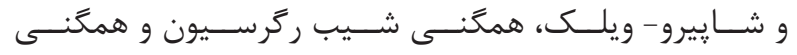

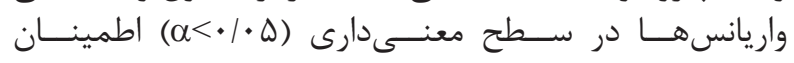

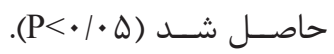

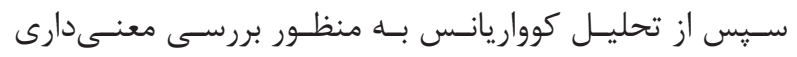

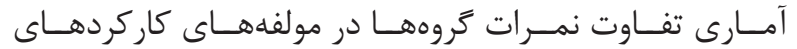

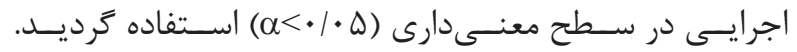

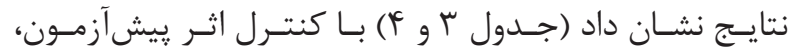

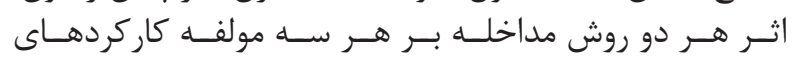

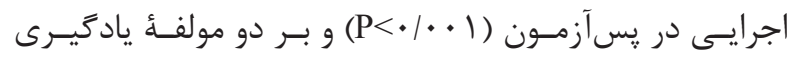

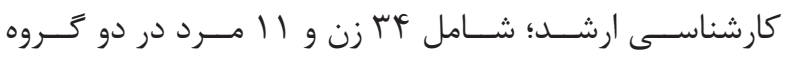

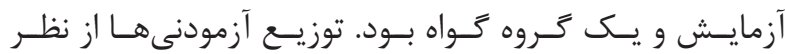

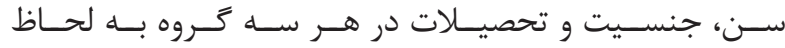

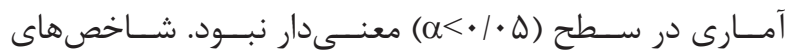

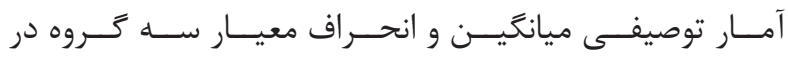

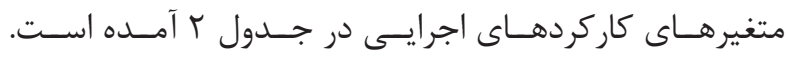

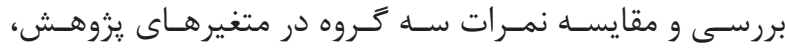

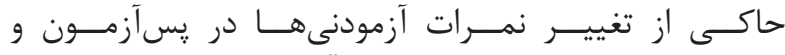

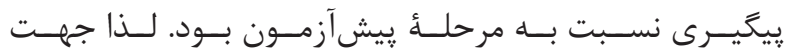

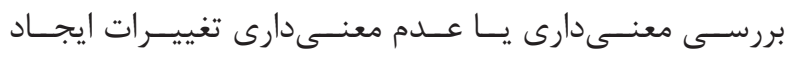

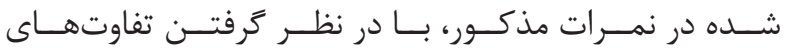

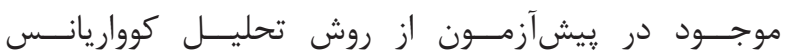


جدول r- ميانگَين و انحراف معيار نمرات گروهها در مولفههاى كاركردهاى اجرايى در مراحل يِيشآزمون، يّآزمون و يِيخيرى

\begin{tabular}{|c|c|c|c|c|c|c|c|}
\hline \multicolumn{2}{|c|}{ بيقيَيرى } & \multicolumn{2}{|c|}{ بس آزمون } & \multicolumn{2}{|c|}{ بيش آزمون } & \multirow{2}{*}{ مر مروه (A) } & \multirow{2}{*}{ متغير } \\
\hline انحراف معيار & ميانكين & انحراف معيار & ميانَين & أحراف معيار & ميانكين & & \\
\hline$r / \mu l$ & 101.9 & $1 / a$ & YKAFG & $1 / Q f$ & $10 / 4 r$ & فعالسازى & \\
\hline $1 / Q T$ & $10 / 94$ & $T / \mu$. & $M E / T$. & I/AY & $10 / \lambda$ & اكت & انعطافيذيرى فكرى \\
\hline$r / \cdot 9$ & I & $r / I F$ & $1 Q / \Lambda$. & $r / \cdot r$ & $|Q /|^{4}$. & كواه & \\
\hline $1 / 1 V$ & $4 \cdot 14 \pi$ & $1 / 14$ & $4 \cdot 149$ & $1 / \pi \Lambda$ & $99 \mathrm{NT}$ & فعالسازى & \\
\hline $1 / \pi f$ & 49194 & $1 / \lambda r$ & $94 / .9$ & $1 / \pi \omega$ & 99149 & اكت & يادَّيرى قوانين \\
\hline 1/QT & 9Q/NY & $1 / \pi V$ & $9 Q / \cdot \cdot$ & 1/Ar & Ga/NK & كواه & \\
\hline $1 / A r$ & $\Delta V / T$. & $1 / 9$. & $A V / Y G$ & $1 / 11$ & $99 / 14$ & فعالسازى & \\
\hline $1 / 1$. & $90 / 49$ & $r / \mu \Lambda$ & $19 / 14$ & $1 / 94$ & $90 / \Delta T^{2}$ & اكت & بازدارى \\
\hline $1 / 11$ & $94 / 94$ & $1 / 11$ & $94 / 19$ & $r / T$ & $94 / 99$ & كَواه & \\
\hline
\end{tabular}

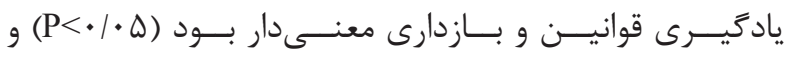

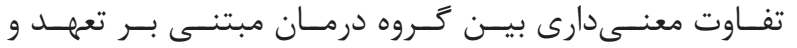

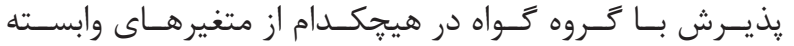

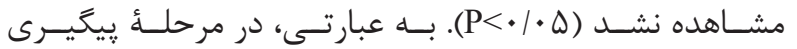

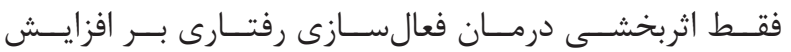

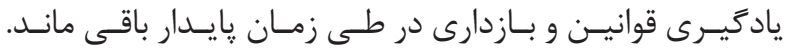

بحث و نتيجه

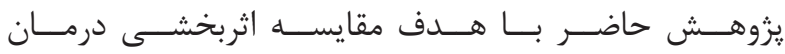

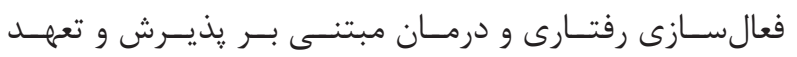

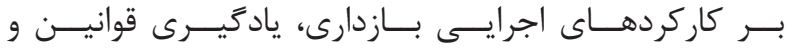

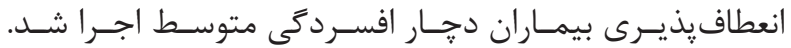

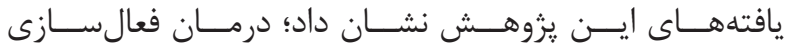

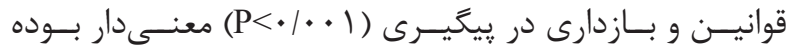

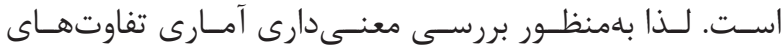

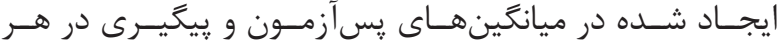

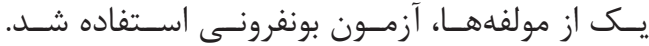

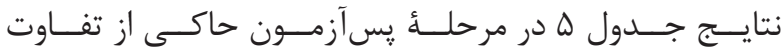

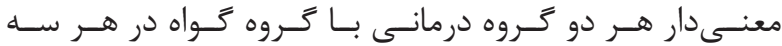

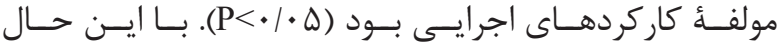

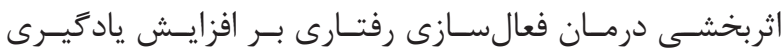

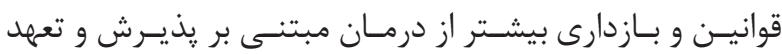

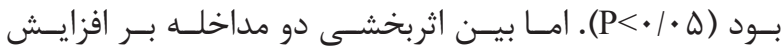

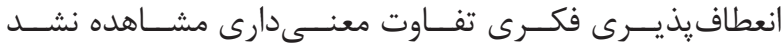

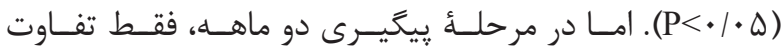

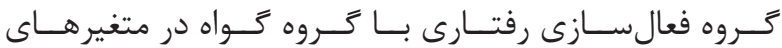

جدول بـ آزمون تحليل كواريانس קندمتغيرى بر روى ميانكين نمرات يسآزمون كروهها در مولفههاى كاركردهاى اجرايى

\begin{tabular}{|c|c|c|c|c|c|c|c|}
\hline$n^{2}$ & $\mathbf{P}$ & $\mathbf{F}$ & MS & df & SS & منبع تغييرات & متغير \\
\hline$\cdot /$ / F & $\cdot 1 \cdot \cdots 1$ & سוr/ & $f \mid / 91$ & 1 & $|f| / 9 \mid$ & يِيش آزمون & \multirow{3}{*}{ انعطافيذيرى فكرى } \\
\hline \multirow[t]{2}{*}{ - /NF } & $\cdot 1 \cdots$ & IIT/KA & س T/K & r & VIr/fes & كروه & \\
\hline & & & T/lf & (i) & ITN/GT & خطا & \\
\hline $.1 \cdot 9$ & $\cdot 11 \cdot 4$ & T/VG & $\Delta / V \Delta$ & 1 & $\Delta / V \Delta$ & ي پيش آزمون & \multirow{3}{*}{ يادكَيرى قوانين } \\
\hline \multirow[t]{2}{*}{$\cdot / 9 V$} & $\cdot / \cdots$ & $F r / \Delta q$ & $\wedge N / 9)$ & r & IVV/Tr & كروه & \\
\hline & & & $r / \wedge$ & \&l & $\Lambda \Delta / \Gamma \cdot$ & خطا & \\
\hline$\cdot / 41$ & $\cdot 1 \cdot r$ & $11 / 10$ & rN/DV & 1 & rN/QV & يِشآزمون & \multirow{3}{*}{ بازدارى } \\
\hline$\cdot / \vee \wedge$ & $\cdot 1 \cdots$ & $V \mathrm{~N} / \Delta \Lambda$ & $r \Delta f / f \varphi$ & r & $\Delta \cdot N / 9 T$ & كروه & \\
\hline & & & $r / f \Delta q$ & 41 & IFI/AT & خطا & \\
\hline
\end{tabular}


جدول F- آزمون تحليل كواريانس جندمتغيرى بر روى ميانكَين نمرات بيخيرى كروهها در مولفههاى كاركردهاى اجرايى

\begin{tabular}{|c|c|c|c|c|c|c|c|}
\hline$\eta^{2}$ & $\mathbf{P}$ & $\mathbf{F}$ & MS & df & SS & منبع تغييرات & متغير \\
\hline - /NF & $\cdot / \cdots$ & $r t / I V$ & $\mid f r / g r$ & 1 & IFT/G & يِيش آزمون & \multirow{3}{*}{ انعطاف يذيرى فكرى } \\
\hline س & $\cdot / 4 \wedge 9$ & - /VYA &.$/ F V T$ & r & $9+\pi / 48$ & كروه & \\
\hline & & & $\cdot \mid 94 \lambda$ & (f) & TG/DG & خطا & \\
\hline . & $\cdot 1 \cdots$ & fE/f & ५q/rq & 1 & एq/५q & يِيش آزمون & \multirow{3}{*}{ يادكيرى قوانين } \\
\hline.$/ 91$ & $\cdot 1 \cdots$ & rIV/af & $\mid 1 F / 48$ & r & TEN/9T & كروه & \\
\hline & & & - /AFG & \&) & re/v. & خطا & \\
\hline . & $\cdot / \cdots$ & 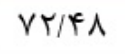 & $9 \cdot|9|$ & 1 & $9 \cdot|8|$ & يِيش آزمون & \multirow{3}{*}{ بازدارى } \\
\hline - & $\cdot 1 \cdots$ & $V M / \Delta \Lambda$ & wff/ls & $r$ & 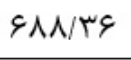 & كروه & \\
\hline تح & & & $1 / K \Delta$ & f) & $\Delta 1 / T \Delta$ & خطا & \\
\hline
\end{tabular}

جدول ه- نتايج آزمون تعقيبى بونفرنى براى مقايسٔ زوجى مولفههاى كاركردهاى اجرايى در كروههاى يروهش

\begin{tabular}{|c|c|c|c|c|c|}
\hline \multicolumn{2}{|r|}{ يخيخيرى } & \multicolumn{2}{|c|}{ هس آزمون } & \multirow{2}{*}{ كرووهاى مقايسه } & \multirow{2}{*}{ متغير } \\
\hline $\mathbf{P}$ & ميانكين تفاوت ها & $\mathbf{P}$ & ميانكين تفاوت ها & & \\
\hline $1 / \cdots$ & $-\cdot 1 \cdot \Delta$ & $\cdot 1 \cdots$ & $N / T \Delta$ & فعالسازى و گواه & \multirow{3}{*}{ نعطافيذيرى فكرى } \\
\hline$\cdot|\Lambda|$ & $\cdot / T \Delta$ & $\cdot 1 \cdots$ & $N / 10$ & اكت و كواه & \\
\hline$\cdot / \Delta V$ & $-\cdot|f|$ & $1 / \cdots$ & .119 & فعالسازى و اكت & \\
\hline$\cdot 1 \cdots$ & $-9 / 11$ & $\cdot 1 \cdots$ & $-\Delta / \cdot \Lambda$ & فعالسازى و تواه & \multirow{3}{*}{ يادگيرى قوانين } \\
\hline $1 / \cdots$ &.$/ 1 \mathrm{r}$ &.$\cdots$ & $-r / 4 q$ & اكت و گواه & \\
\hline$\cdot 1 \cdots$ & $-G / T F$ & $.1 \cdot 49$ & $-1 / 09$ & فعالسازى و اكت & \\
\hline$\cdot / \cdots$ & $-N / T V$ & $\cdot 1 \cdots$ & $-N / \notin q$ & فعالسازى و كواه & \multirow{3}{*}{ بازارى } \\
\hline $1 / \cdots$ & . & $\cdot 1 \cdots$ & $-9 / 49$ & اكت و كواه & \\
\hline$\cdot 1 \cdot \cdots$ & $-N / 9 T$ & $\cdot 1 \cdot \mathrm{rD}$ & $-r / \cdots$ & فعالسازى و اكت & \\
\hline
\end{tabular}

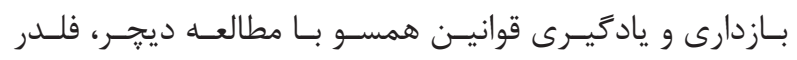

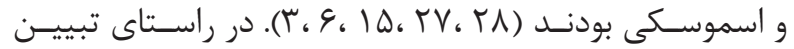

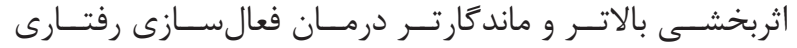

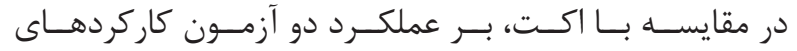

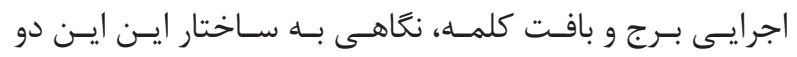

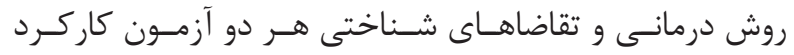

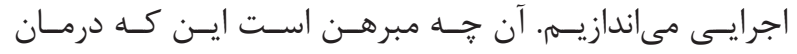

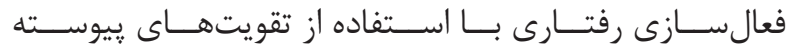

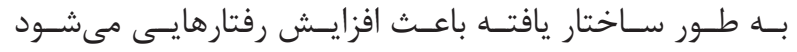

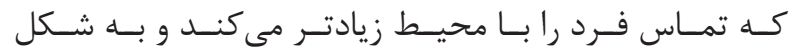

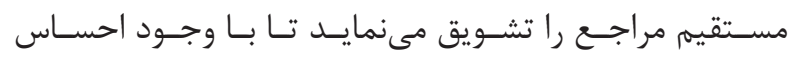

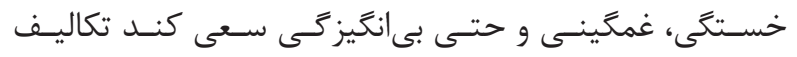

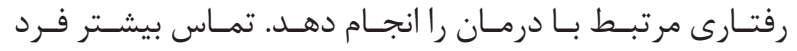

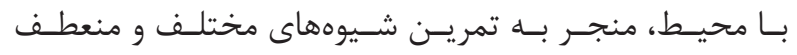

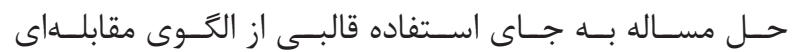

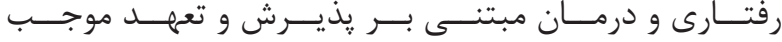

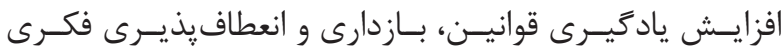

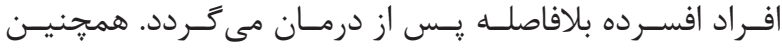

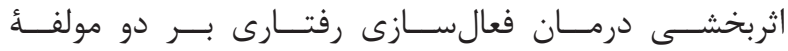

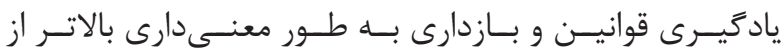

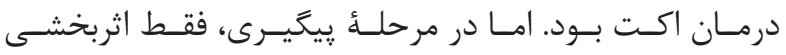

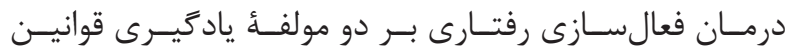

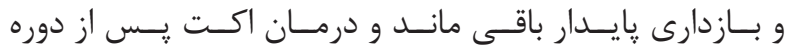

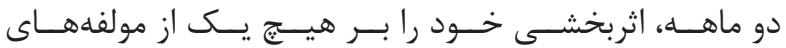

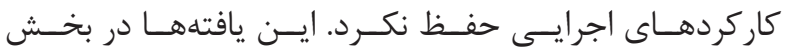

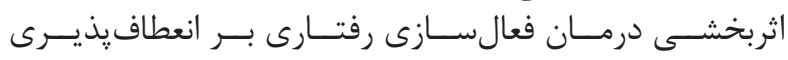

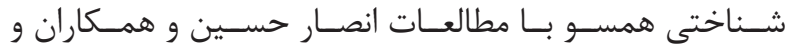

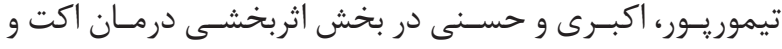

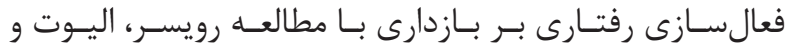

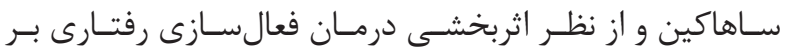




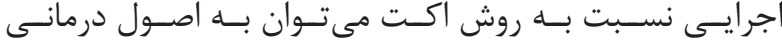

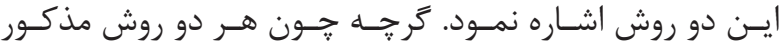

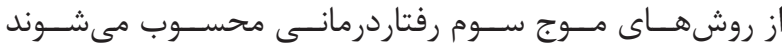

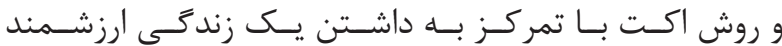

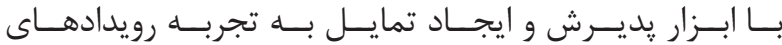

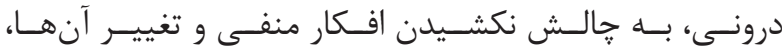

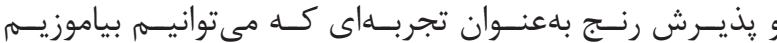

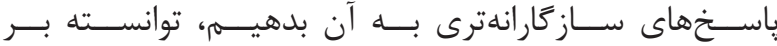

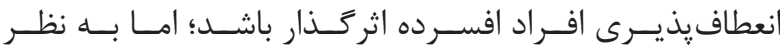

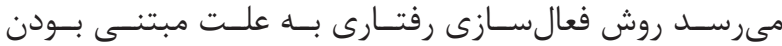

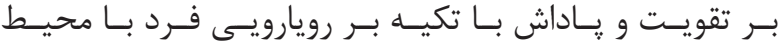

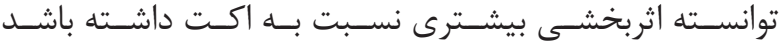

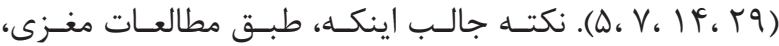

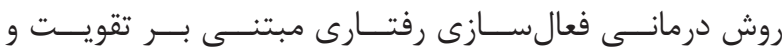

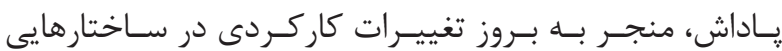

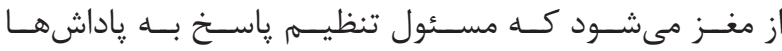

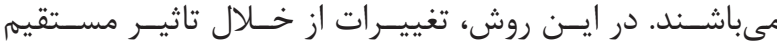

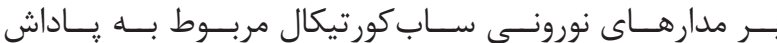

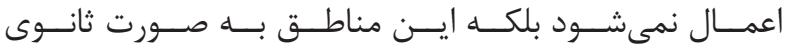

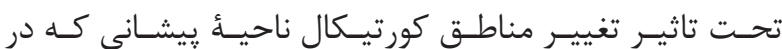

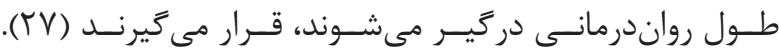

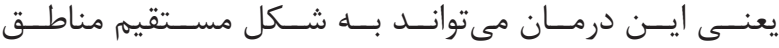

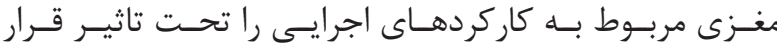

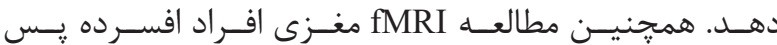

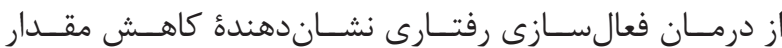

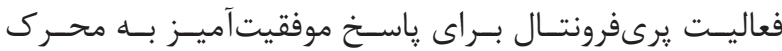

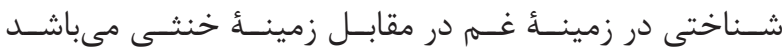

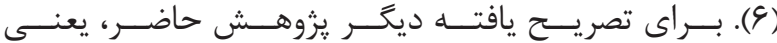

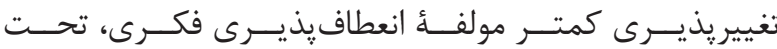

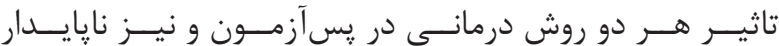

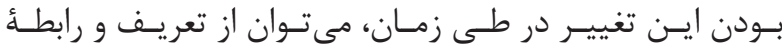

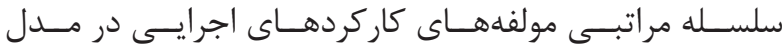

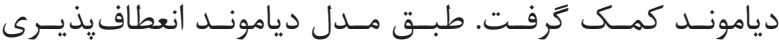

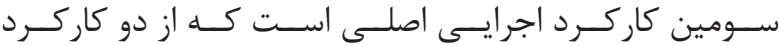

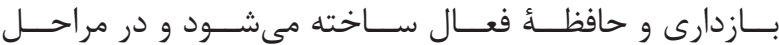

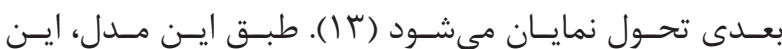

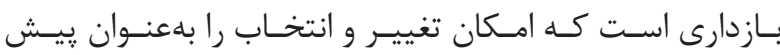

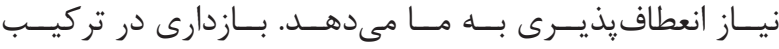

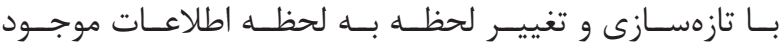

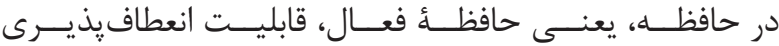

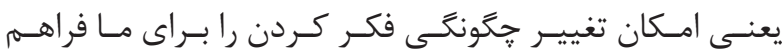

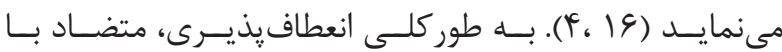

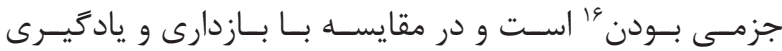

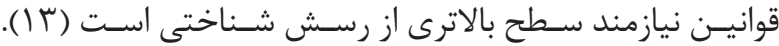

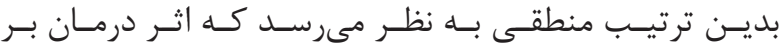

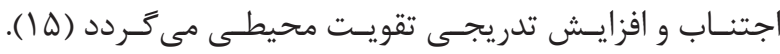

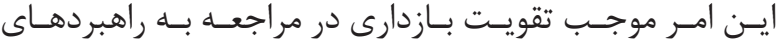

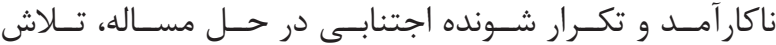

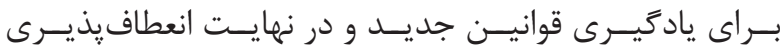

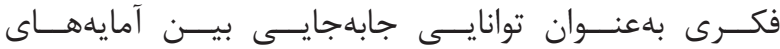

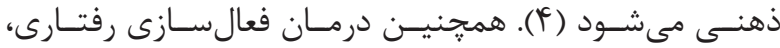

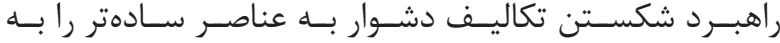

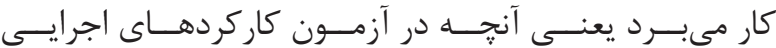

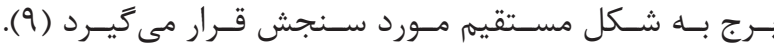

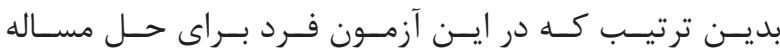

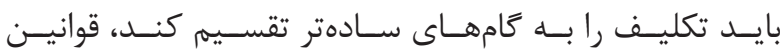

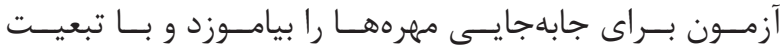

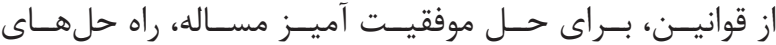

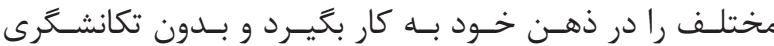

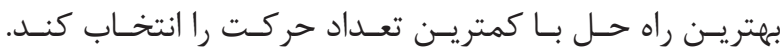

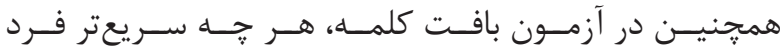

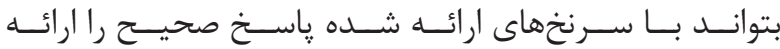

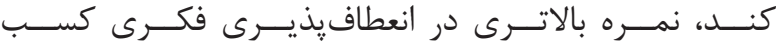

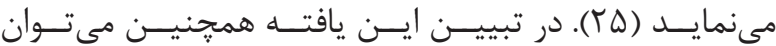

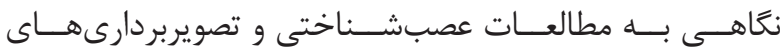

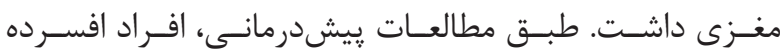

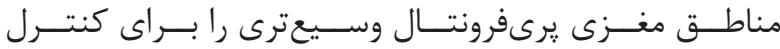

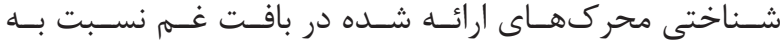

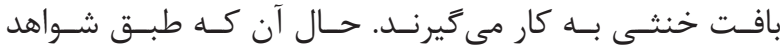

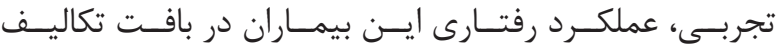

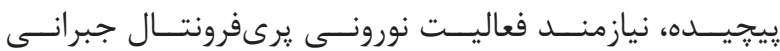

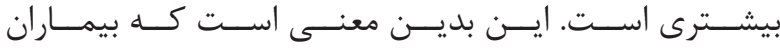

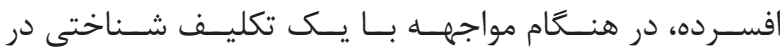

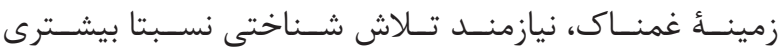

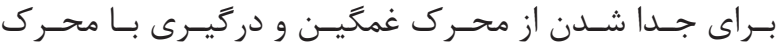

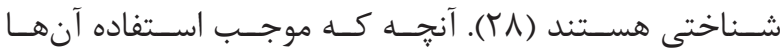

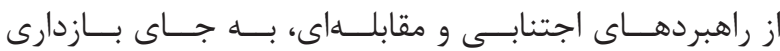

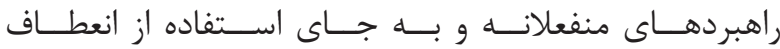

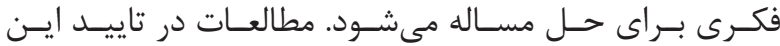

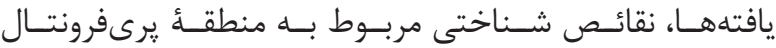

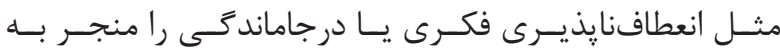

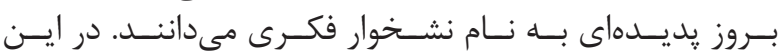

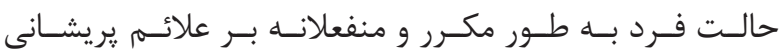

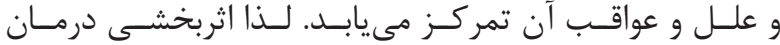

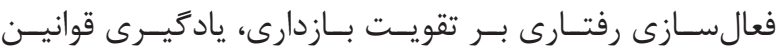

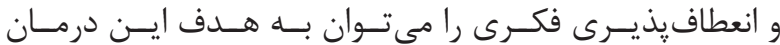

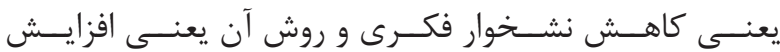

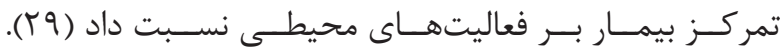

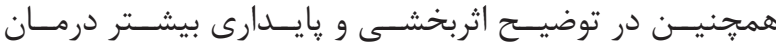

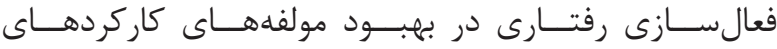




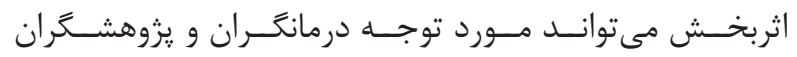

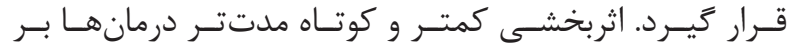

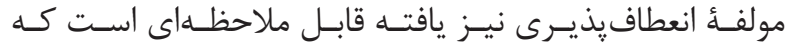

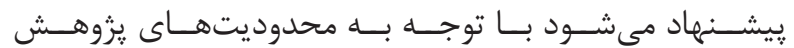

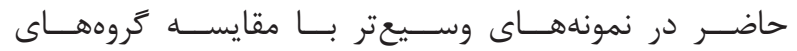

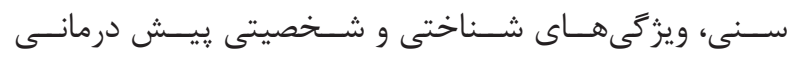

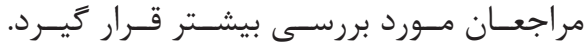

تقدير و تشكر

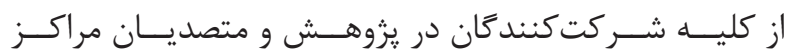

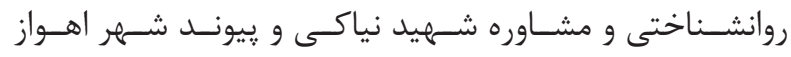

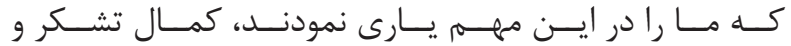
قدردانسى را داريسم.

1. World Health Organization, Depression and other common mental disorders: global health estimates. 2017.

2. Snyder, H.R., Major depressive disorder is associated with broad impairments on neuropsychological measures of executive function: a meta-analysis and review. Psychological bulletin, 2013. 139(1): p. 81.

3. Roiser, J.P., R. Elliott, and B.J. Sahakian, Cognitive mechanisms of treatment in depression. Neuropsychopharmacology, 2012. 37(1): p. 117-36.

4. Koster, E.H. Cognitive control interventions for depression: A systematic review of findings from training studies. Clinical Psychology Review, 2017. 53: p. 79-92.

5. Mori, A. Behavioral activation can normalize neural hypoactivation in subthreshold depression during a monetary incentive delay task. Journal of affective disorders, 2016. 189: p. 254-62.

6. Dichter, G.S., J.N. Felder, and M.J. Smoski, The effects of brief behavioral activation therapy for depression on cognitive control in affective contexts: an fMRI investigation. Journal of affective disorders, 2010. 126(1-2): p. 236-44.

7. A-Tjak, J.G. Explicit and implicit attachment and the outcomes of acceptance and commitment therapy and cognitive behavioral therapy for depression. BMC Psychiatry, 2020. 20: p. 1-11.

8. Azizi, A. and S. Ghasemi, Comparison the effectiveness of solution-focused therapy, cognitive-behavior therapy and acceptance and commitment therapy on depression and quality of life in divorced women. Culture of

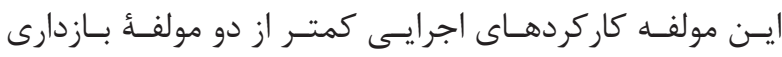

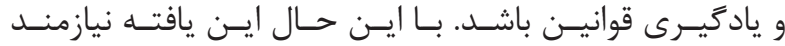

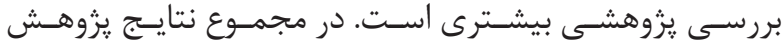

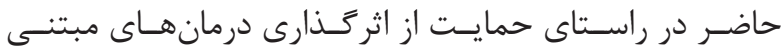

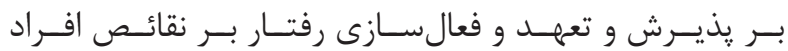

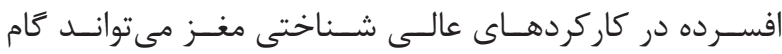

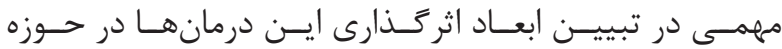

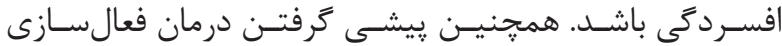

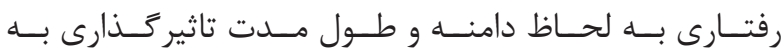

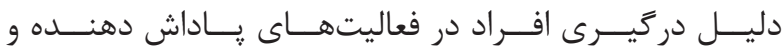

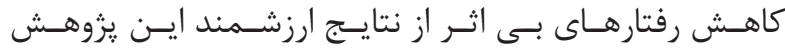

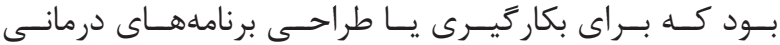

منابع

counseling and psychotherapy, 2017. 8(29): p. 207-36.

9. Valian, A.M. The Effectiveness of Behavioral Activation Therapy on Depression Symptoms and Cog-nitive-Behavioral Avoidance for Students. Quarterly Journal of Social Work, 2017. 5(4): p. 31-25.

10. Dimidjian, S. The origins and current status of behavioral activation treatments for depression. Annual review of clinical psychology, 2011. 7: p. 1-38.

11. Gifford, E.V. Does acceptance and relationship focused behavior therapy contribute to bupropion outcomes? A randomized controlled trial of functional analytic psychotherapy and acceptance and commitment therapy for smoking cessation. Behavior therapy, 2011. 42(4): p. 700-15.

12. American Psychiatric Association, Diagnostic and Statis tical Manual of Mental Disorders IV (DSMIV). 2000: American Psychiatric Pub.

13. Diamond, A., Executive functions. Annual review of psychology, 2013. 64: p. 135-68.

14. Kanter, J.W., D.E. Baruch, and S.T. Gaynor, Acceptance and commitment therapy and behavioral activation for the treatment of depression: Description and comparison. The Behavior Analyst, 2006.29(2):p. 161-85.

15. Teymoorpur, S., M. Akbari, and J. Hasani, The evaluation of mechanism of Effectiveness of Behavioral Activation Therapy (BA) through Cognitive Flexibility and Emotional Flexibility on Symptoms of Women with Major Depressive Disorders. Cognitive Psychology, 2019. 6(4): p. 1-10. 
16. Miyake, A. The unity and diversity of executive functions and their contributions to complex "frontal lobe" tasks: A latent variable analysis. Cognitive psychology, 2000. 41(1): p. 49-100.

17. Majoor, B. Illness perceptions are associated with quality of life in patients with fibrous dysplasia. Calcified tissue international, 2018. 102(1): p. 23-31.

18. Reavell, J. Effectiveness of cognitive behavioral therapy for depression and anxiety in patients with cardiovascular disease: a systematic review and metaanalysis.Psychosomaticmedicine, 2018.80(8):p.742-53.

19. Miller, K.J. Effect of a computerized brain exercise program on cognitive performance in older adults. The American Journal of Geriatric Psychiatry, 2013. 21(7): p. 655-63.

20. Stuss, D.T., Functions of the frontal lobes: relation to executive functions. Journal of the International Neuropsychological Society: JINS, 2011. 17(5): p. 759.

21. Hunnicutt-Ferguson, K., D. Hoxha, and J. Gollan, Exploring sudden gains in behavioral activation therapy for major depressive disorder. Behaviour Research and Therapy, 2012. 50(3): p. 223-30.

22. Saatchi, M., M. Askarian, and L. Pashai, Psychological tests 2. 2019, Tehran: Virayesh.
23. Kanter, J.W., A.M. Busch, and L.C. Rusch, Behavioral activation: Distinctive features. 2009: Routledge.

24. Bond, F.W. and D.W. Hays, Handbook of brief cognitive behaviour therapy. 2005: John Wiley \& Sons.

25. Delis, D.C. Reliability and validity of the DelisKaplan Executive Function System: an update. Journal of the International Neuropsychological Society: JINS, 2004. 10(2): p. 301.

26. Ghawami, H. Cross-cultural adaptation of executive function tests for assessments of traumatic brain injury patients in southeast Iran1. Psicología Conductual, 2016. 24(3): p. 513.

27. AnsarHosain, S. Effectiveness of behavioral activation treatment on asymmetry of alpha EEG in frontal lobe, cognitive flexibility and selective attention in patients suffering from depressive disorder. Thought $\&$ Behavior in Clinical Psychology 2018. 12(48): p. 67-76.

28. Dichter, G.S., J.N. Felder, and M.J. Smoski, Affective context interferes with cognitive control in unipolar depression: an fMRI investigation. Journal of affective disorders, 2009. 114(1-3): p. 131-42.

29. Leahy, R.L., S.J. Holland, and L.K. McGinn, Treatment plans and interventions for depression and anxiety disorders. 2011: Guilford press. 